\title{
A UTILIZAÇÃO DOS DADOS HISTÓRICOS NO ESTUDO DAS CHEIAS DO TEJO
}

\author{
M. TERESA M. AZEVÊDo *
}

Resumo

Abstract
No intuito de colmatar a deficiência de informação hidrológica para o estudo das cheias do Tejo, realizou-se pesquisa histórica intensiva bem como observações de campo e cartogrảficas detalhadas.

Ao longo desta pesquisa tornaram-se claras, não só as variações de percurso do rio, mas tambén a migração das suas barras e a modificação na própria tipologia, passando ao longo dos últimos séculos de um sistema «braided» de múltiplos canais separados por extensas barras arenosas a um rio de canal único de barras alternadas.

A actividade antrópica foi a principal responsável por esta modificação, muitas vezes causada apenas por interesses e ambições pessoais, como é o caso dos «acrescidos», autêntícas colagens das barras ou mouchões às margens por colmatação dos canais, realizadas pelos proprietários ribeirinhos, com o objectivo de aumentarem as suas terras de cultivo. Esta prática foi proibida em finais do século XVIII. Outras vezes, grandes obras de engenharia destinadas a tornarem o rio mais navegível e menos perjgoso, já que ocorriam numerosos naufrágios com lamentáveis perdas de vidas, eram as responsáveis pelas mudanças citadas.

No entanto, o caso mais surpreendente é aquele em que o Príncipe D. Luis solicitou a seu irmão, o rei D. João III, a mudança do percurso do Tejo de $1 \mathrm{~km}$ mais para norte, num troço rectilineo de $10 \mathrm{~km}$ de comprimento, entre Tancos e Chamusca, devido aos prejuizos causados pelo manto de areias que todos os anos cobria, um pouco mais, as suas terras de cultivo.

Essa mudança foi autorizada e novo canal foi aberto ao mesmo tempo que o Velho Tejo era entuihado com pedras e areia. O rio não aceitou, porém, o novo traçado e em poucos anos um outro canal, agora bastante sinuoso e passando junto à Quinta da Cardiga foi naturalmente aberto, erodindo rapidamente as terras de cultivo dos monges da Ordem do Templo.

Este episódio, relatado pelo historiador Alves Dias em 1984, é aqui apresentado, dando-se especial ênfase aos relatos das testemunhas, os quais são transcritos no português do século XVIII, no intuito de encontrar uma hipótese explicativa para a migração lateral do rio e respectiva erosão acelerada.

Palavras-chave: Tejo Velho, Tejo Novo, mudança, século XVI, erosão, Tancos, Lagoa Fedorenta

Using historical data in the Tagus flood's study - To fill the lack of hydrological information to the study of the Tagus' floods, an intensive historical and a detailed cartographic research was made.

Through this research, it was clear not only the river channel's variations but also it's typology, changing over the last four centuries from a braided system with branched channels separated by large sand bars to a low sinuosity river with alternate bars.

The anthropic activity was the main responsible for this change, often caused by personal interests and ambitions, like the artificial «gluing» of the bars to the banks (called «acrescidos») by the marginal owners, in order to increase their agricultural lands.

However, the most amazing case is the one in which the Prince D. Luis, brother to the king of Portugal D. João III, requests permission to change the Tagus' course between Tancos and Chamusca, due to the river sand deposition that every year ruined it's cultivations causing big damages. The Tagus was then pushed $1 \mathrm{~km}$ to the north in a $10 \mathrm{~km}$ long section and a new, perfectly straight channel was opened. However, the river didn't accept this new course. It began to meander and eroded an area of $30 \mathrm{~km}^{2}$ in only 15 years, causing great damages, now to the Order of Christ monks, that again asked the king to shift the river back to it's original position. The permission was given once more, however, the opposition of a very erudite man prevented this new change.

This historical event is described, giving special attention to the details concerning the whiteness' nar rations presented in their original form, that was the archaic portuguese language. For this reason it makes no sense to present this paper in a different language.

We also try to give an explanation to the later natural change, based on fieldwork and on cartographic and aerial photo observations. As a conclusion, it can be considered that this shift was caused not by progressive and slow erosion of the channel like the witnesses led to think, but to a single or some stronger flood events due to special topographic conditions.

Key words: Old Tagus, New Tagus, XVI century, erosion, floods 


\section{INTRODUÇÃO}

Ao iniciar-se o estudo das inundações históricas do vale do Tejo surgiram algumas dificulaàdès: $:$ documentação historica anterior ao terramoto de 1755 é escassa e o devastador incêndio que destruiu o Arquivo Nacional em 1919 mais contribuiu para a ausência de dados sobre a ocorrência de episódios de cheias anteriores a essas datas. Os dados hidrológicos disponíveis reportam-se a $1872 \mathrm{e}$ mesmo assim estão longe de ser contínuos existindo grandes lacunas de informação.

Procurou-se pois, colmatar o «déficit» de dados hidrológicos com o maior número possível de dados histó-. ricos colhidos em documentos antigos sobreviventes aos incidentes referidos, bem como a todo o tipo de informação existente nos arquivos actuais - Biblioteca Nacional e Torre do Tombo - em bibliotecas locais, compêndios de História, jornais de noticias, arquivos fotográficos, cartografia antiga e actual e mesmo os mais antigos jornais de actualidades do cinema e da televisão.

Foi no decurso dessa intensiva pesquisa bibliográfica que se nos deparou um interessante artigo da autoria de Alves Dias (1984), o qual serviu de base a este trabalho. Tal como o autor refere «é frequente pensar-se que a geografia de um país não se alterou ao longo dos séculos». Ainda que essa perspectiva não se estenda a geólogos e geógrafos, não deixa de ser surpreendente o que se passou com o Tejo no séc. XVI. Por se considerar este episódio de grande importância para o conhecimento do comportamento deste rio ao longo do tempo, apresenta-se um pouco da sua história entre 1550 e 1775.

\section{A MUdanç de percurso do TEJo no SÉc. XVI}

Já Estrabão mencionava a extraordinária fertilidade do Tejo. Apesar de as suas inundações serem frequentemente devastadoras e catastróficas, sempre foram elas as responsáveis pelas mais ricas e produtivas terras agrícolas de Portugal.

Essa preciosa riqueza das suas margens foi cantada por poetas e referida por inúmeros escritores e foi, sem dúvida, a causa da implantação preferencial de povoados desde o Paleolítico (testemunhado pelos milhares de artefactos encontrados no seu Terraço Médio e cuja idade vai do Acheuleuse Médio ao Micoquense, $\approx 120.000$ anos ) (Mozzı ET AL 2000) até à Actualidade.

Contudo, as mesmas cheias que trazem a riqueza sob a forma de vasas e lodos (os denominados «nateiros») podem, ser causa da mais profunda desolação e esterilidade.

A jusante das Portas do Rodão, o seu vale abre-se em ampla planicie aluvial acumulando-se, em gigantescas barras de canal, as areias resultantes da erosão das formações de diferentes idades que o rio atravessa. Essas espessas areias invadem, ,aquando das maiores cheias, os sedimentos finos da planície aluvial impedindo o seu cultivo. E foi justamente essa a razão pela qual surgiu um curioso episódio, hoje já praticamente olvidado, mas que se encontra ainda registado num mapa de 1900 (fig. 1).

A observação do traçado do canal actual do Tejo a Sul de Tancos (fig. 2), não permite perceber que esse traçado resulta de uma luta ciclópica entre o homem e o rio, podendo afirmar-se que o Tejo actual pouco ou nada tem a ver com o seu padrão primitivo ou mesmo com aquele que possuía no inicio da nossa Era. Em particular, na referida região, é difícil imaginar quão diferente foi o seu percurso há cerca de 500 anos apenas.

Também no troço de Almeirim o seu traçado é igualmente muito recente.

\section{O Tejo Velho e o Tejo Novo}

$\mathrm{Na}$ vasta bibliografia sobre a problemática do Tejo, não só relativamente ao melhoramento da produção agrícola e protecção de bens mas também ao da navegabilidade, não faltam referências aos nocivos episódios de invasão das terras de cultivo por areias durante as maiores cheias, cobrindo e danificando campos de cultura. 


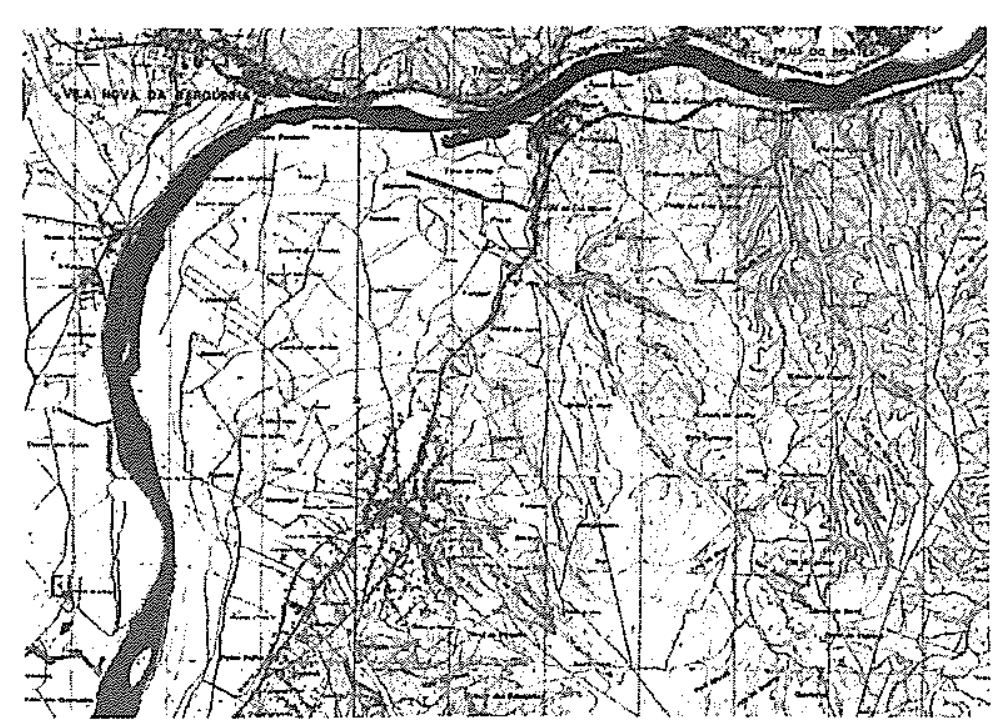

Fig. 2 - Carta topográftca do Entroncamento (n." 330) à escala 1:25.000 de 1992.

Fig. 2 - Topographic map of Entroncamento (Sheet n. 330) at a 1:25.000 scale, from 1992.

Contudo, nas épocas romana e muçulmana, as planícies do Tejo são descritas como só comparáveis às do Nilo, em fertilidade e riqueza agrícola. Essa incomparável produtividade foi sempre atribuida à sedimentação dos «nateiros», fracção mais fina da carga sólida do rio, com cerca de $1 \mathrm{~cm}$ de espessura média, transportada durante as cheias e depositada, cheia após cheia, por decantação lenta na planície de inundação. Em 1861, Júlio Guerra apresenta os primeiros resultados analíticos da sua composição.

A partir dos séc.XIII e XIV começam, a surgir repetidas citações sobre essa cobertura dos terrenos de cultivo e formação de extensos areais, principalmente entre Tancos e Santarém, onde o Tejo corria encostado aos relevos de Arrepiado e Carregueira. Esta progressiva mas contínua erosão e consequente invasão das lezírias por material grosseiro, tem a ver com a cada vez maior àrea desflorestada para dar lugar a plantação hortícula e vinícula. Segundo dados de sondagens em turfeiras e estudos paleobotânicos na região de Alpiarça, foi possível determinar a existência de importante revestimento florestal de carvalhos $\mathrm{e}$ pinheiros, que terá sofrido um primeiro abate importante em meados do XIII milénio a.C. e um novo surto, que não cessou de aumentar, nos ínicios do séc. III, certamente relacionado com a necessidade de criar espaços para a agricultura. A vinha, por exemplo, começou a ser cultivada no actual território português, nos finais do séc.VII a.C., embora existisse já no estado selvagem desde tempos recuados (Matoso, 1997). No séc. XII, é notável a descrição que Osberno, Cruzado inglês do exército empenhado na conquista de Lisboa,(1147) faz acerca da ocorrência de ouro nas margens do Tejo, da abundância de peixe nas suas águas e das extensas plantações de vinhas. Contudo, à medida que a antiga floresta ia sendo desbravada, a erosão acelerava-se aumentando cada vez mais a área dos mouchões, barras arenosas, cuja colagem às margens originando os «acrescidos», aumentava a área agrícola dos proprietários ribeirinhos. Essa desflorestação atingiu o auge no séc. XIX com a construção do Caminho de Ferro.

Em vista da referida situação de profundo assoreamento, surge em 1550 um insólito pedido do Infante D. Luís de Portugal, irmão do rei D. João III, para que o curso do Tejo fosse desviado $1 \mathrm{~km}$ para Norte, de modo a não arear as suas propriedades situadas «a riba de Santarém», que se tornavam areais incultiváveis causando-lhe enormes prejuízos. Essas propriedades situavam-se a Sul da ilha de Almourol, entre uma Iagoa adjacente ao rio e a que chamavam de Fedorenta e a sua margem esquerda. Denominava-se esta propriedade Herdade da Martitinha (fig. 3 e 4). Por outro lado, desde 1169, ano en que D. Afonso Henrique doou todos os terrenos da margem direita do Tejo à ordem do Templo, que esta vasta área pertencia à Quinta da Cardiga com o nome de Campos da Cardiga (fig. 3 e 4 ).

Sendo D. Luís personagem do reino de grande influência, autorizou D. João III a mudança do curso do rio, «tirando-o do alveo a que hoje se chama Tejo Velho, mudando-lhe a corrente para o Tejo Novo por motivo de coitar o impeto das areias que carregavam as lezirias das Barrocas que ficavam por cima de Santarémis.

Em vez de correr adjacente aos relevos de Arrepiado, Carregueira e Pinheiro que atingem cotas de $180 \mathrm{~m}$, seguindo depois a actual trajectória já próximo da Chamusca, num troço pouco sinuoso ou mesmo rectilíneo, o rio, desviado $1 \mathrm{~km}$ para Norte, deixaria de transportar as areias provenientes da erosão destes relevos, evitando assim o assoreamento das terras do Infante.

D. João Ill desenvolveu os esforços necessários para evitar tais prejuízos ao irmão lançando o rio «pela parte da Cardiga». Nessa época, Portugal conhecia amplo arroteamento de terras ao longo dos vales dos rios, com abertura de canais, valas e drenagem de paúis, trabalho que tinha já grande tradição no país (DiAs 1984).

Mudou-se pois o traçado «do dito Tejo que custou muito trabalho e muito gasto e vieram muitos Mestres e homens de despejança digo de experiência 


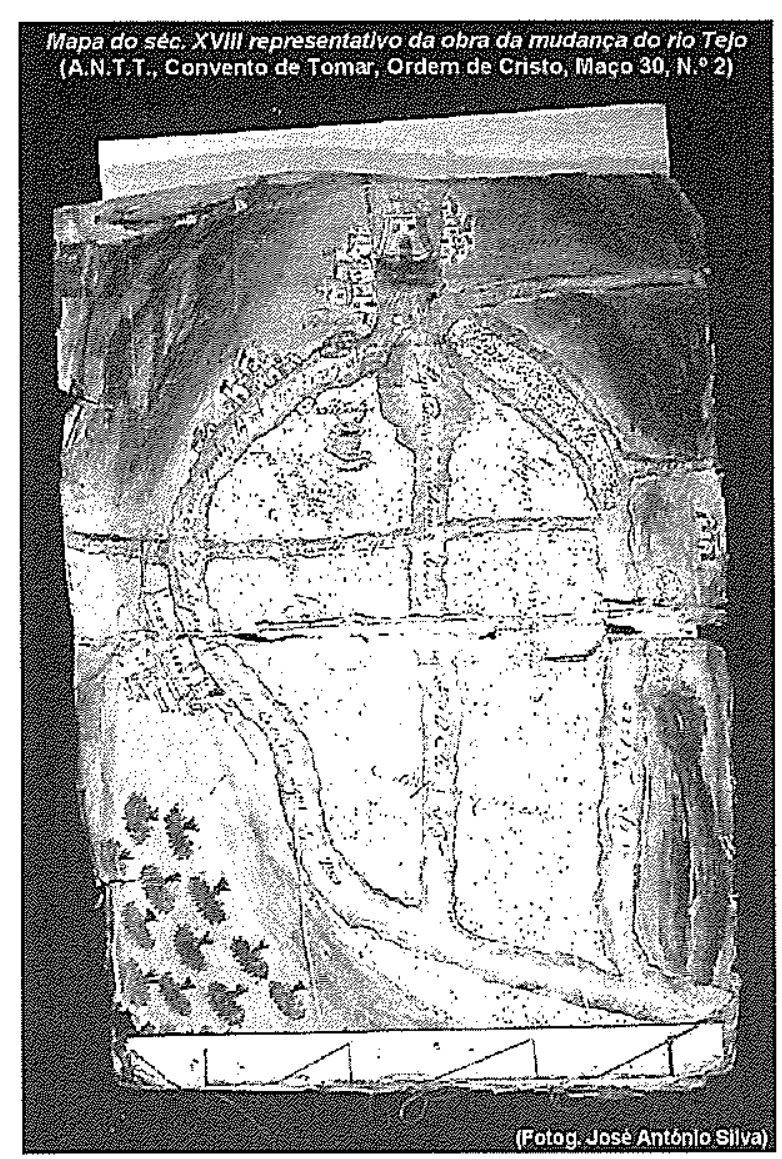

Fig. 3 - Mapa do séc. XVIll representativo da obra de mudança do rio Tejo.

Fig. 3 -XVIIIth century map representing the works related to the changes of the river Tagus.

e trabalharão mais de vinte trinta mil homens por tempo de Julho que acarretaram calhaus e outros entulhos que custou muito dinheiro».

O novo troço, de $10 \mathrm{~km}$ de comprimento, tinha um traçado igualmente rectilíneo (fig. 3 e 4), porém cortava parte dos campos da Cardiga que passaram assim a partilhar ambas as margens; o seu limite Sul deixou pois de ser o Tejo, ao mesmo tempo que os terrenos da Coroa, cujo limite Norte era o rio velho, ficaram adjacentes aos da Ordem de Cristo. Esses novos limites não causaram na altura qualquer problema entre as duas entidades proprietárias.

Entulhado o Velho Tejo, foram os terrenos transformados em coutada «havendo ai couteiros que demandavam as penas ás pessoas que nelas encorria», sendo proibido por ordem real aí pescar, passar ou navegar a fim de impedir que as areias se movessem.

Vários mapas antigos, nomeadamente os mapas de Portugal na escala 1:100.000 de 1855 e 1:50.000 de 1900 assinalam uma ribeira denominada ainda nessa época Tejo Velho e que resultava da escorrência das águas provenientes dos relevos da margem Sul mos-

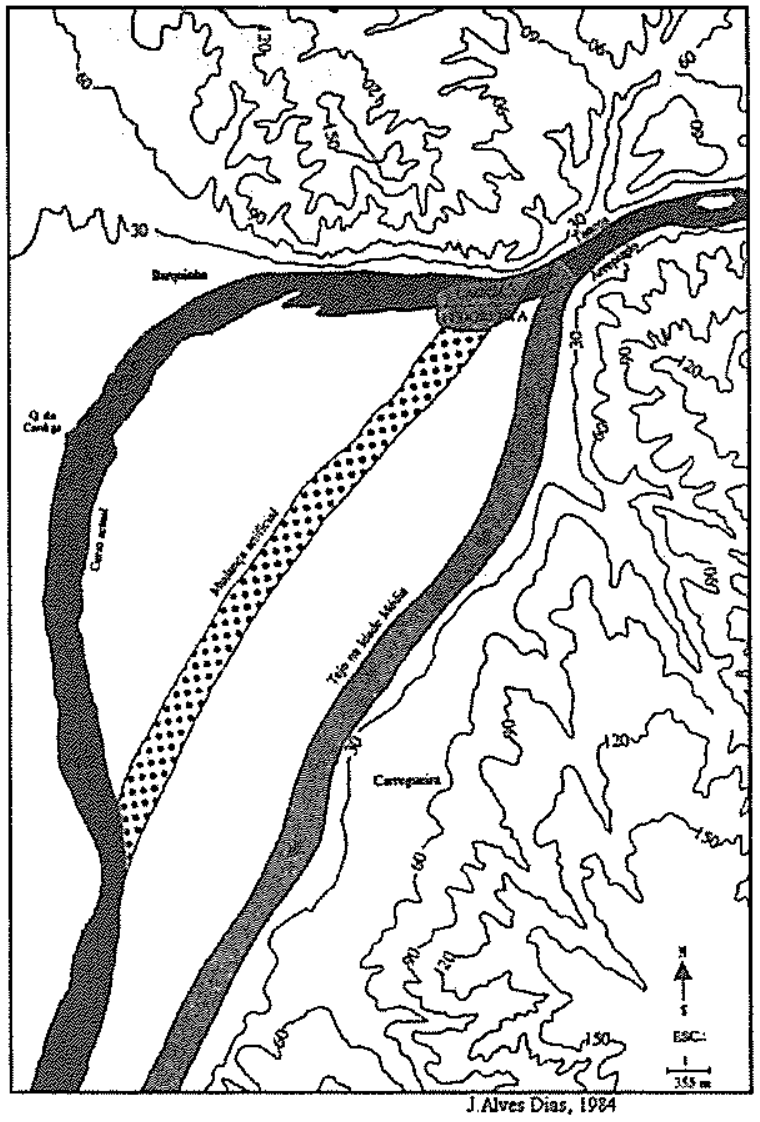

Fig. 4 - Esquema interpretativo (Alves DIAS 1984) da mudança artificial do rio Tejo no século XVI.

Fig. 4-Interpretative sketch (Alves DiAs 1984), of the artificial change of the river Tagus in the XVIth century.

trando que as areias não tinham sido totalmente imobilizadas como se pretendia (fig. 5).

$\mathrm{O}$ novo troço ou Tejo Novo saído, segundo as crónicas, da Lagoa Fedorenta directa e rectilíneamente para sul, não «agradou», porém, ao rio que escolheu novo traçado deslocando-se cada vez mais para Norte e tornando-se progressivamente mais sinuoso, desenvolvendo ampla curvatura a Norte da Lagoa Fedorenta. E, como consequência da erosão provocada na margem côncava da curva que se formava, foram desaparecendo as terras de cultivo da Quinta da Cardiga.

Com uma taxa de erosão elevadíssima, em cerca de 15 anos erodiu toda a área que ia do canal artificial até às casas da Quinta às quais passava (e passa) adjacente (fig. 2), de tal modo que, no dizer de uma testemunha, anteriormente ao desvio, «quando os Padres haviam de ir embarcar em algum barco, por não poderem ir a pé, iam em cavalgaduras e agora vai já por junto das casas da Cardiga»(fig. 6).

Em 1565 os Padres da Ordem de Cristo vendo este devorar de terras pelo rio solicitaram ao rei, então 
D. Sebastião, que voltasse a colocar o Tejo no antigo percurso, já que os prejuízos arcavam em $300 \$ 000$ reais e a obra custaria $150 \$ 000$ reais. Dispunham-se mesmo a pagar os trabalhos juntamente com outros pequenos proprietários igualmente prejudicados pela mudança.

Segundo os tombos das comendas da Cardiga e de Almourol de 1504, o campo da Cardiga produzia então mais de 50 Moios de semeadura e a área situada entre o Tejo Novo e o Velho, cerca de 600 Moios $(\sim 496,8 \mathrm{kl})$, sendo necessários 80 criados para tratar da grande quantidade de gado existente. Depois da mudança, a área de cultivo diminuiu tanto que os campos cultivados produziam apenas 300 a 330 Moios, ou seja, cerca de metade.

Como argumentação para o seu pedido o Dom Prior dos religiosos do convento de Tomar referiu que o rei D. João ... «fez mudar o rio Tejo do curso antigo e natural que levava e levou sempre de tempos e idades imemoriais aquella parte correndo de antes direjto emthé ao longo das Carrigueyras e das terras de António do Seme e que a mudança o fizera correr de novo ao longo das terras da Quinta da Cardiga do dito convento abrindo para isso novas covas a que foi cauza imediata com que o dito Tejo lhes tem levado das ditas suas terras da Cardiga mais de dez moios de semeadura e todos os dias lhes estão levando com continuo e perpétuo damno e com qualquer cheya lhes destroye as novidades e tem feito duas alvergas entradas pelas ditas terras que está prometendo antes de dez anos com quaisquer cheias sem nenhum Remédio acabar de lhes levar e estruir de todo as ditas terras da dita quinta e porque o dito convento foi e hé inurmisumamente lezo da dita mudança do Tejo $e$ nunca nella deu consentimento nem foi sobre isso houvido e por razão della se lhes perde toda a dita quinta de que se sustentão. Pede a Vossa Alteza havendo todo o respeito mande que o dito Rio seja tornado ao dito primeiro curso natural e antigo que levava ao tempo que foi mudado»...

Os prejuizos advinham ainda do pisoteio das terras cultivadas por todos aqueles que constantemente transportavam mercadorias de e para o rio. Também aí foram decretadas medidas de protecção, que consistiram principalmente em demarcar um local único onde o embarque das mercadorias era permitido. Os barqueiros que aportassem fora desse local pagariam uma multa de 600 reais na primeira vez e ficariam encarcerados 30 dias nas demais vezes. Esse local foi-se logicamente desenvolvendo com o aumento das transações realizadas por via fluvial e, a barca, elemento desse desenvolvimento, ficou na origem da toponímia - Barquinha - situada próximo da actual Vila Nova da Barquinha, a qual, não existia, nem como porto nem como povoado, antes de 1527 (como salienta Alves Dias), pois o Tejo não passava por aí.
Concedida a autorização d'el-rei para que «possão lançar e tornar o rio do Tejo por onde antigamente Soia de Vier, abaixo da vila de Tancos, e não tendo essa obra sido realizada 15 anos depois (1572), ordenou $D$. Sebastião um inquérito sobre os prejuizos causados pela mudança do rio e se devem ou não voltar ao curso antigo». Como Portaria pede ao Provedor da comarca de Santarém se informe acerca do pedido no sentido de averiguar se «a obra que os Padres querem fazer e o lugar por onde querem mudar o curso do rio e se darão prejuizos ao Povo ou se será menos o prejuizo vir o rio pelo curso que dantes tinha ou hir por onde agora vay e assy houvirá os officiães das cameras cumarcas ...».

Iniciado o Inquérito, o próprio Provedor d'el-rei, licenciado João Homem, declara como causa do assoreamento do Tejo e como argumento para que a nova mudança não se realizasse que: «tinha o Tejo suas grandes Ribas e quebradas de area da parte do sul e munte grandes $e$ altos fitos em carnocos e de munta infinita quantidade de Comprimento e de meia légoa de serros do rio as quais cahiam sobre o Tejo que hera cauza e destruição de todos os Campos e Lezírias athé Lisboa que ao longo do dito Tejo estam e assim da navegação dos Barcos porque tundo tinhão entulhado as agoas das cheias que passavam ao longo dos ditos serros dareya, pelo que seria de grande prejuizo de todo o reyno tornar se a mudar o Tejo por onde levava o curso antigo e tanto que se acabariam de perder os campos Lezirias e terras do dito Tejo mudando sse por onde antiguamente sohia de hir $e$ assy se perderia a villa de Tancos fazendo sse the preza para tomar a agoa e ser por onde passa porque com as cheyas tornaria a agoa atras e alagaria a Villa e a mayor e melhor parte dela se perderia...».

Continua ainda mais adiante «com as ditas serras de areya hindo o Tejo por elas como pellas areyas que trazem os Ribeyros que vem dar ao Tejo da parte das areyas abayxo donde foi mudado que vem das charnecas e terras novas que se nellas fazem e que portanto é impossivel poder se fazer o que os Padres pedem...»

Em 1590 nova petição foi apresentada. Foram então convocados vários lavradores, de idades compreendidas entre 60 e 84 anos, que haviam nascido e crescido nessas terras e que se lembravam perfeitamente da mudança passada; testemunharam tanto o assoreamento antigo da Herdade da Martitinha como a erosão devastadora recente da Quinta da Cardiga: depois de devidamente «louvados e ajuramentados aos santos evangelhos, relataram tudo o que sabiam, estimando as perdas em 17 moios de pão de trigo, 19 de semeadura e 12 de cevada, desde que o Tejo passara a correr pela dita quinta. Declararam ainda que « quando a agoa viesse em muy poucos anos levará e romperá o campo de bayxo que levara de semeadura otro tanto». 
Todos esses testemunhos de 1590, ou seja, 40 anos após a mudança, são unânimes em relação às perdas observadas, mencionando que o Tejo teria feito perder à Quinta da Cardiga mais de 50 Moios de semeadura e que antes o rio estava meia légua afastado das casas e agora passava perto delas. Outro facto em que há pleno consenso é em responsabilizar a grande erosão provocada pelo rio pelo facto de ele ter sido lançado «pela Fedorenta». O próprio Prior do Convento de Tomar afirma: "he verdade que El Rey Dom João terceiro que está na glória mandou mudar o Tejo e o lansou pela fedorenta por onde agora vay e mandou com penas que ninguém navegasse ou pescasse pelo braço da Carregueira» e mais à frente continua: "mais de cincuenta moios de semeadura que o Tejo levou e lhe leva ainda agora todos os invernos tanto que com o Tejo ao tempo que ia pelo braço da Carregueira estar afastado das cazas da Cardiga perto de meya légoa vay agora por perto das Casas».

Prevaleceu porém a opinião do Provedor de Santarém, limitando-se o rei a conceder uma indemnização aos Padres da Ordem de Cristo.

O Tejo estabilizou finalmente após desenhar o amplo sinuosidade que percorre actualmente. Nas cartas mais modernas não existe já qualquer referência ao Tejo Velho ou ao canal artificial por onde quiseram «obrigá-lo» a correr. No entanto, a actual Ribeira do Vale da Feiteira com cabeceira na área correspondente à Lagoa Fedorenta, correndo rectilíneamente para Sul numa estreita depressão, pode eventualmente corresponder ao que resta desse canal. $O$ rio continua a passar tangente às Casas da Cardiga e, ainda que afastado dos relevos de Arrepiado e Carregueira, continuou a assorear a região, o que se pode comprovar tanto pelo espesso manto de areias que cobre esses terrenos como pelas extensas barras que se dispõem ao longo do canal.

Em 1735 surgiu finalmente a contenda entre a Ordem de Cristo e a Coroa quando os representantes desta pretenderam medir e demarcar a lezíria da Martitinha. Em 1511 esta situava-se na margem direita do Tejo, porém a tradição oral sustentava que ela se situava na margem esquerda.

A Ordem de Cristo afirmava, com razão, que os terrenos da margem esquerda sempre tinham sido seus, o que mudara fora o curso do Tejo. A Coroa defendia que a fronteira Norte das suas terras era 0 Tejo e que todos os terrenos até ao rio lhe pertenciam.

Este problema originou um pleito jurídico e foi esse processo que juntou toda a documentação que constitui o Maço 30 dos Conventos de Tomar de 1735, hoje arquivados no ANTT.

Este não foi, porém, o único desvio sofrido pelo canal do Tejo. No reinado de $\mathrm{D}$. João $\mathrm{V}$ há referências sobre o deslocamento do rio na região de Almeirim, afirmando Leite de Vasconcelos, em 1936, que nessa data existia ainda um sítio cascalhento próximo da vila, denominado Tejo Velho. Também refere que em 1922, numa noticia do DN sobre cheias na região de Santarém, se aplicava a mesma designação. Uma elucidativa gravura do tempo de $\mathrm{D}$. João $\mathrm{V}$ alusiva ao trabalho de abertura do novo canal, foi publicada pelo autor na mesma obra (fig. 5).

No Elogio Fúnebre de D. João V, refere F.X. da Silva em 1750: «Fez sua Majestade abrir o Tejo, com grande comodidade do comércio, em ordem a se poder navegar com segurança e a toda a hora, por ser perigosíssimo a passagem que franqueava às navega-

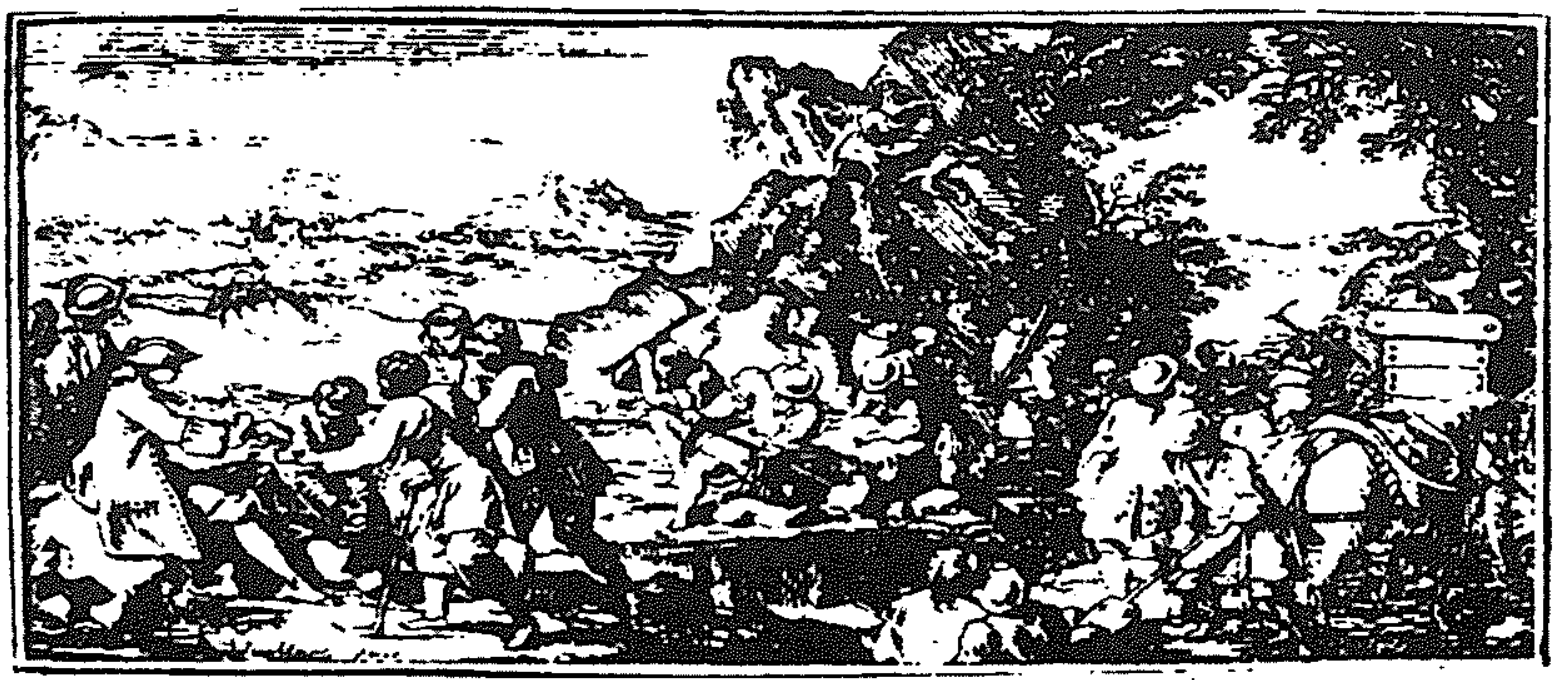

Fig. $5-$ Gravura que representa a mudança do percurso do Tejo no reinado de D. João V (século XVIII), in Leite de Vasconcelos (1936)
Fig. 5 - Illustration that represents the change of the course of the Tagus in the reign of D. Joano V (XVIIIth century), in Leite de Vasconcelos (1936) 
ções, dando-se o nome a este sítio de Novo Tejo, com o que evitou o Augusto Monarca na repetição dos naufrágios a perda de vidas, e das fazendas, de que muitas vezes ou por força dos temporais, ou por incúria dos pilotos, não podia escapar das suas perigosissimas voltas».

Muitas outras obras se seguiram, principalmente nos séculos XVII e XVIII destinadas a tornar o Tejo navegável. Durante a ocupação espanhola um dos grandes objectivos dos monarcas reinantes, era o possibilitar a ligação entre Lisboa e Madrid, através do Tejo. Foram então realizadas importantes obras de limpeza do canal ao longo de todo o seu percurso, tendo sido possível a navegabilidade até Toledo durante um curto espaço de tempo A partir da reconquista, esse objectivo deixou de ter sentido e em pouco tempo o canal ficou novamente obstruido principalmente pelos proprietários ribeirinhos que tinham visto os seus improvisados pesqueiros e portos destruidos a dinamite.

No entanto, nenhuma dessas obras foi tão ambiciosa como as duas aqui citadas.

\section{Questōes POSTAS POR eSte RElato}

Para além do grande interesse histórico que estes relatos possam ter, é possivel que através pelo menos do primeiro (do qual possuímos neste momento mais elementos de análise) se possam colocar algumas questões e dar algumas respostas.

a. Quais as taxas de erosão entre 1550 e 1565 ?

b. Se o troço original era rectilíneo e estável porque razão o canal artificial, também rectilíneo e deslocado apenas $1 \mathrm{~km}$ para Norte, se tornou tão rapidamente instável começando a meandrar?

c. Porque razão a Lagoa se denominava Fedorenta? Se era por a água aí ficar estagnada, porquê essa brusca diminuição de energia?

d. Quando recuperou o Tejo a sua estabilidade?

e. Onde se situam os dois canais anteriores?

Este é também um óptimo exemplo e confirmação das nefastas consequências de alterar o curso de um rio sem análise prévia da sua dinâmica e comportamento.

\section{Algumas respostas prÉvias às questōes ANTERIORES}

De acordo com o texto descrito parecia numa 1." análise que após a mudança artificial, o Tejo teria iniciado um processo de meandrização progressiva e rápida erodindo as terras de cultivo situadas na margem direita do novo canal, até estabilizar junto à Quinta da Cardiga.

As avaliações feitas pelos agricultores das perdas dessas terras em moios de trigo, cevada ou semeadura levaram-nos a tentar calcular a velocidade de erosão com que, apenas em 15 anos, o rio, devastou toda aquela área. Para isso procurou-se a equivalência do Moio, derivado da antiga medida àrabe Mekkar: 1 Moio $=60$ Alqueires. Ao mesmo tempo, com as equivalências:

1 Alq. de centeio $\sim 5640 \mathrm{~m}^{2}$ e 1 Alq. de trigo $\sim$ $2820 \mathrm{~m}^{2}$

calculou-se a área erodida e avaliou-se a taxa de sedimentação.

No entanto, na continuação do trabalho, ao analizar-se mais detalhadamente o comportamento do rio ao longo do tempo, tanto a partir da cartografia antiga e actual e da foto aérea como dos relatos históricos, chegou-se á conclusão de que essa erosão não poderia ter sido progressiva ainda que rápida, resultante de processos naturais da dinâmica fluvial em que o rio teria começado a meandrar por variação no tipo de carga do leito ou porque "o meandro representa a forma pela qual os rios executam o seu trabalho pelo esforço mínimo" (LEOPOLD E LANGBEIN 1966), mas teria resultado sim, do facto de o novo canal artificial ter sido traçado rectilineamente a partir da Lagoa Fedorenta, através de terrenos cuja cota era superior à dos adjacentes à Lagoa na sua margem norte.

A análise cartográfica e histórica confirma essa conclusões.

\section{ANÁlise CARTOGRäfica}

A análise detalhada de inúmeros mapas do Tejo, o mais antigo dos quais data de 1796, mostra que ele era até ao século XIX um rio anastomosado, de múltiplos canais separados por barras arenosas, por vezes de grandes dimensões, obedecendo à definição de sistema anastomosado de Smith e Putnam(1980).

Essas barras ou Mouchões, (de que são exemplos no troço a jusante de Tancos, o do Inglês, o dos Coelhos, o do Alfange, o do Conde da Vidigueira, etc.), situam-se principalmente na margem esquerda e inicialmente encontravam-se separados desta por estreitos canais deixados para trás pelo afastamento progressivo do canal principal para a margem direita. Até 1934 são claramente visiveis esses braços que conferiam ao rio o referido carácter «braided». A partir dessa data eles tornaram-se meras linhas de água frequentemente intersectadas ou sem continuidade, passando o Tejo a apresentar um canal único muito mais confinado, se bem que as acumulações arenosas, sob a forma de barras, continuem a 
ocorrer abundantemente. São, porém, de muito menores dimensões e dispõem-se alternadamente numa e noutra margen, podendo o rio actual paralelizar-se com o Modelo de Miall (1996) de «rios de um único canal de barras alternadas"y.

A pesquisa histórica indica, por seu lado, que esses mouchões foram, ao longo de séculos «colados» às margens do rio, por colmatação artificial dos canais, formando os «acrescidos». Efectivamente, enquanto a legislação de 1875 não proíbiu essas intervenções na fisionomia do rio, os agricultores viam a área das suas terras de cultura aumentadas, cada vez que faziam a ligação dos terrenos marginais ao mouchão que lhes ficava em face, enchendo o respectivo canal de separação. Estes abusos acabaram por ser punidos, no entanto, grandes áreas marginais actuais resultaram da subtracção de canais secundários do rio por este processo.

Voltando à análise da cartografia, foi possível, através da comparação das cartas de diferentes épocas e escalas (1766 a 1996), avaliar outros aspectos da antiga dinâmica fluvial, hoje desaparecidos. É o caso de extensas áreas de «paúis», terrenos permanentemente encharcados e pantanosos, de que ainda restam alguns, hoje transformados em reservas naturais, como é o caso do Paúl do Boquilobo (fig. 2)

\section{A Lagoa Fedorenta e a mudanç de percurso DO TEJo}

A Lagoa Fedorenta que os documentos históricos situam imediatamente a jusante do «colo» de Tancos seria certamente um local do tipo descrito, adjacente ao rio mas suficientemente afastada para que as suas águas não fossem renovadas. Através de uma detalhada pesquisa de campo na planície aluvial, à saída de Tancos e na margem esquerda do rio, de acordo com a antiga documentação, foi possível encontrar uma extensa área exalando ainda fétido odor, de terreno escuro, essencialmente argiloso, bem circunscrita e contacxtando bruscamente com as areias claras e espessas que ocupam toda a área envolvente. No campo observam-se ainda zonas alongadas deprimidas que, devido à escala, não são visíveis na cartografia e cuja interpretação é difícil visto tratar-se de terrenos arenosos.

Por outro lado, a análise da cartografia antiga e recente mostrou claramente que a barreira de separação entre o rio e a Lagoa seria obrigatoriamente uma área mais elevada situada a $\mathrm{N}$ do canal, de maneira a servir de obstáculo à sua passagem, tanto para o interior da Lagoa como para a área a $\mathrm{N}$ desta.

Acreditando nos relatos das testemenhas, saindo o canal artificial mandado abrir por D. João III justamente da extremidade $\mathrm{S}$ da Lagoa Fedorenta, torna-se claro que o rio passou a atravassá-la percorrendo rectilíneamente a distância que o separava da Chamusca, onde, se juntava novamente com o canal natural.

Ora, nessa situação, já nada o impedia de migrar lateralmente para $\mathrm{N}$ uma vez que a área imediatamente a $\mathrm{N}$ da Lagoa é, como se pode observar tanto nos mapas como no campo, topograficamente mais baixa que a adjacente do lado $S$ (fig. 2). Bastaria então uma simples cheia para o atirar para a depressão que hoje ocupa, logo começando a erodir rapidamente a margem côncava da ampla sinuosidade que se começava a desenhar (Quinta da Cardiga) e depositando na convexa, a qual se ía elevando ainda mais, aí confinando o canal definitivamente.

Seria ainda possível sugerir que a Lagoa Fedorenta fosse, não uma causa mas uma consequência do desvio do rio, resultando das águas estagnadas que aí permaneceram. No entanto, os relatos das testemunhas que presenciaram as obras são unânimes quanto à sua anterior existência. Por outro lado, um «gráfico comparativo da profundidade dos fossos mais notáveis; vaus do Tejo inferior,» da autoria de Costa Veiga , apresenta o traçado correcto do Tejo para a Idade Média, onde representa a Lagoa Fedorenta, e em que afirma ter esta existido até ao reinado de D.João III em que se entulhou o Tejo velho e se rompeu o novo alvéo através da Lagoa Fedorenta.(in DIAS 1984). Parece assim ser credível que ela existisse, de facto, no século XVI.

\section{Conclusōes}

A interpretação avançada para a mudança natural do percurso do Tejo após o deslocamento artificial sofrido no séc, XVI é de natureza puramente topográfica, não parecendo, após análise cuidada de todos os factores intervenientes, estar relacionada com aspectos da dinâmica fluvial, como sejam variações no tipo de carga transportada ou de qualquer outra natureza, as quais provocam usualmente as mudanças na tipologia de certos troços dos sistemas fluviais.

Assim, neste caso, o evento parece relacionar-se apenas com a falta de perspicácia de quem ordenou o percurso artificial, ao não se aperceber de que a Lagoa Fedorenta se situava a cota mais elevada do que o canal doTejo, conduzindo-o facilmente através de algumas cheias mais violentas a adoptar, para o seu leito os terrenos situados nessa margem a cotas mais baixas.

A partir daí, o canal encontrou-se cada vez mais confinado pela deposição de sedimentos na margem convexa da ampla sinuosidade desenhada. 


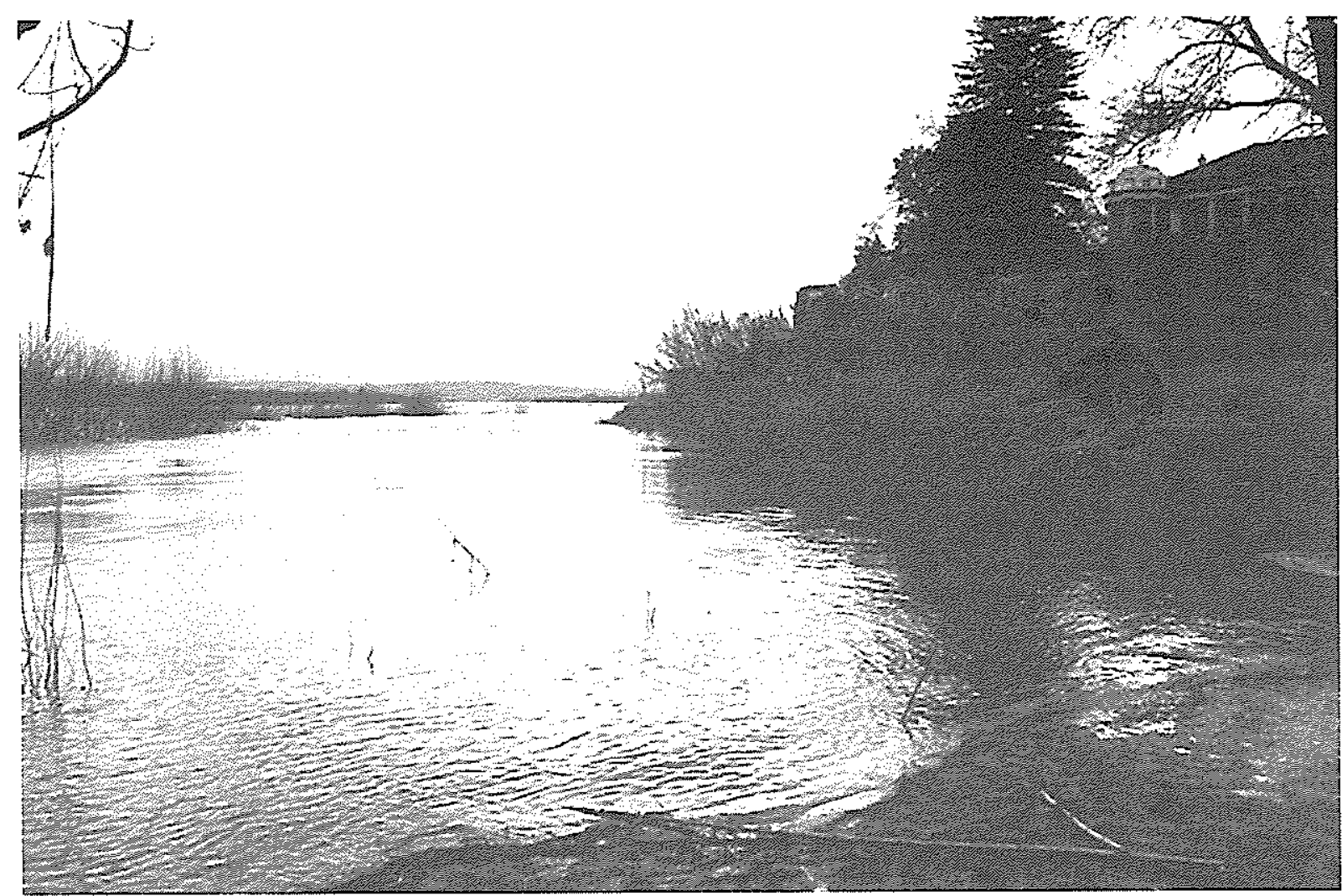

Fig. 6 - Fotografia actual (T. AzEvitoo 2000) do rio Tejo passando junto à Quinta da Cardiga.

\section{AgRadecimentos}

Agradece-se aos Prof.s Suzanne Daveau e Galopim de Carvalho a leitura e melhoramento do texto. Ao colega Jorge Figueiras as sugestões pertinentes, À Dr." Elisabete Nunes a formatação do texto e digitalização das figuras.

\section{BIBLIOGRAFIA}

A.N.T.T., Conventos de Tomar, Ordem de Cristo. Maço $30, n^{\circ} 1$ e 4 (vermelho) fl.21.

Costa Vejga - «Estudos de História Militar Portuguesa», Atlas, vol.1, MapaXI.

DIAS, J. J. ALVES (1984) - «Uma grande obra de engenharia em meados de sec.XVI. Mudança do curso do Rio Tejon, Revista Nova História, ed. Estampa, Lisboa.
Fig. 6-Recent photograph (T. AZIVEEDDO 2000) of the river Tagus going past "Quinta da Cardiga

GUERRA J. (186!) - «Estudos chorograficos, plyysicos e hydrographicos da Bacia do Tejo, compreendida no Reino de Portugal», Lisboa, Imp. Nacional.

LEITE DE VASCONCELLOS (1936) - «Etnografia portuguesa», Imp. Nacional, Vol.1I, pp. 23.

LANGiBEIN W.B. \& LeOPOLD L.B.(1964)- "Quasi-equilibrium states in channel morphologym, Amer. Jour: of Science, 262, (6), 782-794

MiAlL, A.D. (1996) - «The Geology of Fluvial Sedimentary facies, basin analysis and petroleum geology" Springer- Verlag.

MozZI P. AZEvĖdo T.M. Nunes E. RAPoso L. (2000) - «Middle Terrace deposits of Tagus River in Alpiarça, Portugal, in relation with early human occupation?, Quatemary Research, Vol.54, n'3, pp. 359-37I.

OSBzERNO (1147) - «A Conquista de Lisboa aos Mouros em 1147. Carta de um Cruzado Inglês que participou nos acontecimen. tosm, Livros Horizonte, Lisboa

SiLVA F.X. (1750) - "Elogio Fúnebre de D.João V», pp. 234.

SMrth D:G.\& PUTNAM P.E. (1980) - «Anastomosed river deposits: modern and ancient examples in Alberta, Canadan, Canadian Journal of Earth Sciences, 17, 1396-1406. 